\title{
DESENVOLVIMENTO DE BIODIGESTOR E AVALIAÇÃO DO DESEMPENHO PARA TRATAMENTO DE RESÍDUO SÓLIDO ORGÂNICO
}

\author{
F. S. PIO ${ }^{1}$, L. T. SANTANA ${ }^{1}$, L. K. CORRÊIA ${ }^{1}$ e F. D. CASTRO ${ }^{1}$ \\ ${ }^{1}$ Centro Universitário do Leste de Minas Gerais, Departamento de Engenharia Química \\ E-mail para contato: flavia.souza.pio@gmail.com
}

\begin{abstract}
RESUMO - O presente trabalho teve a finalidade de construir e avaliar a eficiência de um biodigestor anaeróbio, para degradação da remoção da matéria orgânica oriunda de dejetos bovinos. O biodigestor foi operado em três ciclos, em processo descontínuo, e o tempo de retenção hidráulica variou de acordo com cada ciclo, tendo duração de 21 a 35 dias. A caracterização dos dejetos foi realizada por meio de amostragens no início, meio e final de cada ciclo. Foram analisados os seguintes parâmetros: temperatura, $\mathrm{pH}$, sólidos totais ( $\mathrm{ST}$ ), sólidos voláteis (SV), sólidos fixos (SF), umidade, demanda química de oxigênio (DQO), amônia e produção de biogás. Os resultados indicaram que o processo de biodigestão anaeróbia foi eficiente para degradar a matéria orgânica dos dejetos bovinos. Para ST, SV, SF, umidade e DQO, foram registradas remoções máximas de $43,31 \%, 39,75 \%, 59,38 \%, 9,88 \%$ e $96,27 \%$, respectivamente, para o efluente resultante do biodigestor. Verificou-se um aumento significativo na produção de nitrogênio amoniacal, sendo o valor máximo obtido de 43,10\%. Foi realizado o teste de chama, o qual comprovou a produção de biogás. Entretanto, não foi possível quantificar a produção de biogás, devido a possíveis vazamentos.
\end{abstract}

\section{INTRODUÇÃO}

O biodigestor anaeróbio consiste em um sistema onde ocorre a fermentação da matéria orgânica (resíduos alimentícios e/ou dejetos animais) por bactérias, na ausência de oxigênio. É uma alternativa para reduzir o acúmulo de dejetos descartados de forma indevida, sendo considerado como uma fonte energética renovável, segura e sustentável. Esse equipamento tem o objetivo de substituir lagoas e terrenos a céu aberto, métodos comumente utilizados para descarte de dejetos em atividades agropecuárias. Segundo o Ibama (1998), pela legislação Ambiental (Lei 9.605 - Lei de Crimes Ambientais), produtores agropecuários podem ser responsabilizados por danos causados ao meio ambiente. Por esse motivo, o biodigestor se torna uma forma eficiente para tratamento de matéria orgânica gerada por essas atividades (Almeida, 2008).

O biogás é um combustível gasoso, com conteúdo energético semelhante ao gás natural, produzido nos biodigestores, a partir da digestão anaeróbia. A sua composição varia de acordo com o tipo de biomassa utilizada e pode conter até $70 \%$ de gás metano $\left(\mathrm{CH}_{4}\right)$, que é combustível, possui elevado poder calorífico e não produz fuligem. O biofertilizante é um efluente do biodigestor que possui propriedades fertilizantes, com elevado teor de húmus, 
composto por: água, nitrogênio, fósforo e potássio, em quantidade e composição adequadas, podendo ser utilizado diretamente na adubação das plantas (Flores, 2014).

O presente trabalho empregou como fonte de matéria orgânica os dejetos bovinos. Tendo em vista a liberação indiscriminada desses dejetos na natureza, a implantação de biodigestores pode ser considerada uma alternativa para a destinação racional dos resíduos, diminuindo seu potencial poluidor, reduzindo sua patogenicidade e adequando os proprietários de bovinos às exigências da legislação ambiental (Ferreira, 2013).

\section{METODOLOGIA}

Com base no estudo de Eckert et al. (2015), optou-se por construir um biodigestor de modelo descontínuo e material de aço inox, de formato cilíndrico, com diâmetro de $22 \mathrm{~cm}$ e altura de $27 \mathrm{~cm}$, com capacidade de 10,264 L. A Figura 1 apresenta o sistema de biodigestão anaeróbia. O biodigestor foi operado em três ciclos distintos, como pode ser observado na Tabela 1.

Figura 1 - Sistema de biodigestão anaeróbia utilizado no experimento

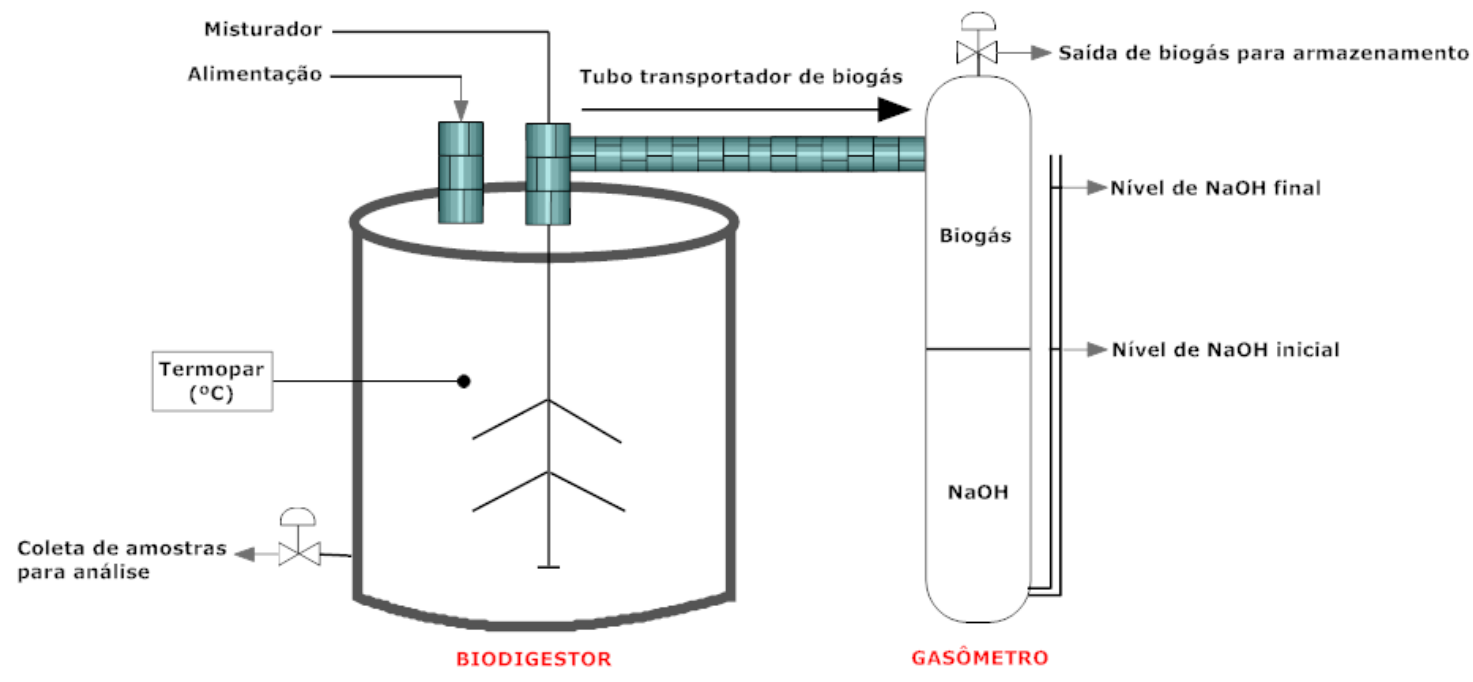

Tabela 1 - Ciclos do biodigestor

\begin{tabular}{|c|c|c|c|}
\hline & $1^{\circ}$ Ciclo & $2^{\circ}$ Ciclo & $3^{\circ}$ Ciclo \\
\hline \hline Início & $08 / 09 / 2016$ & $03 / 10 / 2016$ & $07 / 11 / 2016$ \\
\hline Término & $03 / 10 / 2016$ & $07 / 11 / 2016$ & $28 / 11 / 2016$ \\
\hline $\begin{array}{l}\text { Tempo de } \\
\text { Retenção }\end{array}$ & 25 dias & 35 dias & 21 dias \\
\hline
\end{tabular}

A produção de biogás a partir de dejetos bovinos comumente apresenta grande eficiência, uma vez que cerca de $10 \mathrm{~kg}$ de matéria orgânica produzem $0,40 \mathrm{~m}^{3} / \mathrm{dia}$ de biogás. Dessa forma, optou-se por trabalhar com esse tipo de matéria orgânica. Além disso, é um material de fácil acesso, que pode ser obtido em grande quantidade. Para inseri-lo no processo, não é necessário o uso de inóculo, já que possui microrganismos capazes de degradar a carga orgânica (Fundação Aperam Acesita, 2011). 
Foram analisados os seguintes parâmetros, para o processo de biodigestão anaeróbia: $\mathrm{pH}$, pressão, temperatura, sólidos totais (ST), voláteis (SV) e fixos (SF), umidade, demanda química de oxigênio (DQO), nitrogênio amoniacal e produção de biogás. As análises de sólidos, umidade, DQO e nitrogênio amoniacal foram realizadas de acordo com a Apha (2005), no início, meio e fim do processo de biodigestão. $\mathrm{O}$ pH foi verificado com o pHmetro. A produção do biogás e a pressão foram controladas a partir do gasômetro, acoplado na câmera digestora. Para verificar a temperatura, foi utilizado um termopar. Estas análises foram realizadas a cada três dias, durante o processo.

\section{RESULTADOS E DISCUSSÃO}

Com base nas dimensões propostas, foi construído o biodigestor anaeróbio, como observa-se na Figura 2. Os resultados das análises para o primeiro ciclo não foram considerados, pois o biodigestor estava em fase de teste.

Figura 2 - Sistema de biodigestão anaeróbia

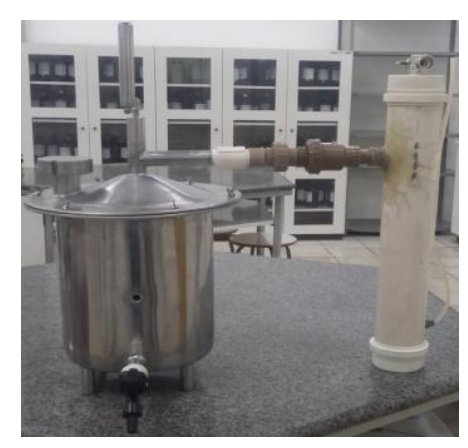

Os valores de temperatura e $\mathrm{pH}$ mostraram-se satisfatórios, pois estavam dentro das faixas ideais, de $25^{\circ} \mathrm{C}$ a $36^{\circ} \mathrm{C}$ e 7 a 8 , respectivamente. Portanto, não limitaram o processo.

\subsection{Teor de sólidos}

A partir dos dados da Tabela 2, pode-se observar que houve remoção significativa dos ST, SF e SV. Estes valores estão de acordo com os resultados de Vivan et al. (2010), que encontraram resultados para remoção de ST de $24,16 \%$, SF iguais $12,72 \%$ e SV de $34,63 \%$, o que comprova que o presente trabalho apresentou taxas de degradação de sólidos satisfatórias.

Tabela 2 - Valores dos parâmetros ST, SF e SV para início e fim do processo de biodigestão

\begin{tabular}{|c|c|c|c|c|c|c|c|c|c|c|c|}
\hline \multicolumn{3}{|c|}{ Sólidos Totais (ST) - g/L } & \multicolumn{3}{c|}{ Sólidos Fixos (SF) - g/L } & \multicolumn{3}{|c|}{ Sólidos Voláteis (SV) - g/L } \\
\hline \hline Ciclo & Início & Fim & $\begin{array}{c}\text { Remoção } \\
(\%)\end{array}$ & Ciclo & Início & Fim & $\begin{array}{c}\text { Remoção } \\
(\%)\end{array}$ & Ciclo & Início & $\begin{array}{c}\text { Fim } \\
\text { Remoção } \\
(\%)\end{array}$ \\
\hline 2 & 88,20 & 50,00 & 43,31 & 2 & 16,00 & 6,50 & 59,38 & 2 & 72,20 & 43,50 & 39,75 \\
\hline 3 & 74,30 & 67,83 & 8,71 & 3 & 13,10 & 12,63 & 3,58 & 3 & 61,20 & 55,20 & 9,80 \\
\hline
\end{tabular}

\subsection{Umidade}

A Tabela 3 evidencia os teores de umidade da matéria orgânica, para o $2^{\circ}$ e $3^{\circ}$ ciclos. 
Tabela 3 - Teores de umidade do biofertilizante

\begin{tabular}{|c|c|c|c|c|c|}
\hline Ciclo & \multicolumn{3}{|c|}{$2^{\circ}$} & \multicolumn{2}{c|}{$3^{\circ}$} \\
\hline $\begin{array}{c}\text { Coleta da } \\
\text { amostra }\end{array}$ & Início & Meio & Final & Início & Final \\
\hline Umidade (\%) & 8,09 & 3,98 & 7,55 & 6,96 & 9,88 \\
\hline
\end{tabular}

Observou-se um aumento no teor de umidade da segunda etapa da análise para a terceira. Na primeira etapa do processo, ocorre a fermentação por meio de uma hidrólise, levando ao consumo de água e à redução da umidade. Na última etapa, ocorre a metanogênese, etapa final no processo global de degradação anaeróbica da matéria orgânica biodegradável em metano e dióxido de carbono, em que ocorre a formação de água e, portanto, leva a um aumento da umidade da biomassa. A Equação 1 e a Equação 2 mostram a etapa metanogênica (Biarnes, 2016). Assim, os resultados indicam que ocorreu a metanogênese.

$$
\begin{aligned}
& \mathrm{CO}_{2}+4 \mathrm{H}_{2} \rightarrow \mathrm{CH}_{4}+2 \mathrm{H}_{2} \mathrm{O} \\
& \mathrm{CH}_{3} \mathrm{COOH} \rightarrow \mathrm{CH}_{4}+\mathrm{CO}_{2}
\end{aligned}
$$

\subsection{Demanda Química de Oxigênio (DQO)}

Os resultados das análises de DQO para os ciclos de operação podem ser visualizados na Tabela 4. As análises de DQO no segundo ciclo indicaram que houve uma remoção de 96,27\% para esse parâmetro. Resultados similares foram obtidos por Scapinello et al. (2011), cujo sistema de tratamento anaeróbio empregado apresentou uma grande remoção de DQO, com média de $94 \%$. No terceiro ciclo, verificou-se que houve uma remoção de $53,22 \%$ de DQO. O menor valor de remoção observado para esse parâmetro deve-se, possivelmente, ao menor tempo de processo, conforme exibe a Tabela 1.

A avaliação da DQO é uma forma de quantificar a matéria orgânica presente no biodigestor. Com isso, as remoções de DQO apresentadas nas análises indicam que os resíduos foram, em grande parte, digeridos, satisfazendo os objetivos do processo.

Tabela 4 - Resultados das análises de DQO

\begin{tabular}{|c|c|c|c|}
\hline \multirow{2}{*}{ Ciclo } & $\begin{array}{c}\text { Coleta da } \\
\text { amostra }\end{array}$ & $\begin{array}{c}\text { Concentração } \\
\left(\mathrm{mgO}_{2} / \mathrm{L}\right)\end{array}$ & \multirow{2}{*}{ Remoção (\%) } \\
\hline \hline \multirow{2}{*}{$2^{\circ}$} & Início & 240000 & \multirow{2}{*}{96,27} \\
\cline { 2 - 3 } & Final & 8950 & \multirow{2}{*}{53,22} \\
\hline \multirow{2}{*}{$3^{\circ}$} & Início & 189542,318 & \\
\cline { 2 - 3 } & Final & 88663,683 & \\
\hline
\end{tabular}

\subsection{Teor de amônia}

Os resultados obtidos, que indicaram elevação substancial de amônia, foram esperados. Isso se deve à produção de amônia durante a degradação da matéria orgânica nitrogenada. A Tabela 5 mostra a porcentagem de aumento de amônia nos ciclos. 


\section{Congresso Brasileiro de Engenharia Química \\ em Iniciação Científica \\ UFSCar - São Carlos - SP \\ 16 a 19 de Julho de 2017}

Tabela 5 - Resultados das análises de amônia no $2^{\circ}$ e $3^{\circ}$ ciclos

\begin{tabular}{|c|c|c|c|}
\hline \multirow{2}{*}{ Ciclo } & $\begin{array}{c}\text { Coleta da } \\
\text { amostra }\end{array}$ & $\begin{array}{c}\text { Concentração } \\
(\mathrm{mgN} / \mathrm{L})\end{array}$ & \multirow{2}{*}{ Variação (\%) } \\
\hline \hline \multirow{2}{*}{$2^{\circ}$} & Início & 2556,064 & \multirow{2}{*}{43,10} \\
\cline { 2 - 3 } & Final & 4492,652 & \multirow{2}{*}{12,16} \\
\hline \multirow{2}{*}{$3^{\circ}$} & Início & 4632,610 & 5274,280 \\
\cline { 2 - 3 } & Final & \multicolumn{2}{|c|}{} \\
\hline
\end{tabular}

\subsection{Teste de chama}

A Figura 3 mostra o teste de chama realizado no laboratório, com uma parte da amostra final do segundo ciclo. Pode-se concluir que houve produção de biogás a partir da matéria orgânica utilizada no biodigestor, devido o crescimento da chama, ao entrar em contato com o gás proveniente do béquer contendo os dejetos.

Figura 3 - Teste de chama para amostra de bancada

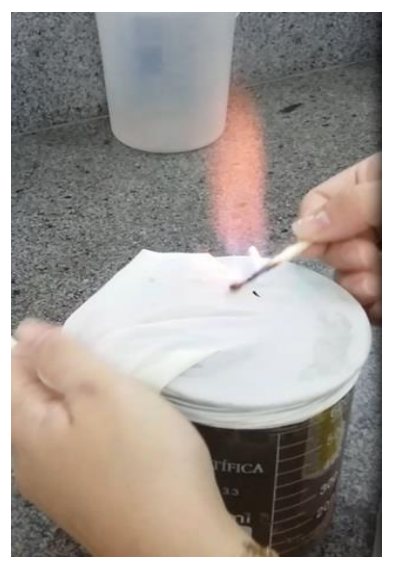

\section{CONCLUSÃO}

O processo de biodigestão anaeróbia apresentou eficiência na remoção dos parâmetros físicos e químicos analisados. Os percentuais máximos de remoção de ST (43,31\%), SF $(59,38 \%)$, SV $(39,75 \%)$, umidade $(9,88 \%)$ e DQO $(96,27 \%)$ indicaram que ocorreu a biodegradação parcial dos dejetos bovinos.

A partir da redução da umidade observada entre a primeira e segunda análise de cada ciclo, pode-se concluir que houve consumo de água, provavelmente devido à etapa de hidrólise. Posteriormente, verificou-se um aumento da umidade, devido à ação de bactérias metanogênicas, que são responsáveis pela degradação anaeróbica da biomassa, decompondo-a em gás metano e gás carbônico e produzindo água nesta reação. Durante cada ciclo, constatou-se um aumento relevante na produção de nitrogênio amoniacal, indicando que a matéria orgânica complexa foi degradada em compostos mais simples, levando à liberação de amônia no meio. 
Foi possível comprovar, a partir dos resultados obtidos, que houve a produção de biogás. Entretanto, a quantificação do gás produzido não foi possível, devido ao tempo insuficiente de operação ou ao possível vazamento no sistema que, consequentemente, fez com que a válvula de retenção não recebesse a pressão necessária para permitir a passagem do biogás para o gasômetro. A formação de gás metano foi confirmada com o aumento do teor de umidade e o teste de chama. Portanto, o biodigestor promoveu a redução da matéria orgânica dos dejetos bovinos, diminuindo o impacto ambiental desse resíduo, ao ser lançado no solo e em corpos d'água.

\section{REFERÊNCIAS}

ALMEIDA, G. V. B. P. de. Biodigestão Anaeróbica na Suinocultura. 2008. 54 f. Trabalho de Conclusão de Curso (Graduação em Medicina Veterinária) - Centro Universitário das Faculdades Metropolitanas Unidas, São Paulo, 2008.

APHA. Standard methods for the examination of water \& wastewater. $21^{\text {st }}$ ed. Washington, D.C.: American Public Health Association, v.1, 2005.

BIARNES, M. Biomass to biogas: anaerobic digestion. 2016.

ECKERT, C. T.; FRIGO, E. P.; MARI, A. G.; MARI JUNIOR, A.; CABRAL, A. C.; GRZESIUCK, A. E.; DIERINGS, L. S. Construção de biodigestores de batelada para escala laboratorial. Revista Brasileira de Energia Renovável, v. 4, p. 65-82, 2015.

FERREIRA, J. Produção de biogás e funcionamento de biodigestores no ensino de Ciências. 2013. 44 f. Monografia (Especialização no Ensino da Ciência) - Universidade Tecnológica Federal do Paraná, Curitiba, 2013.

FLORES, M. C. Viabilidade econômica do biogás produzido por biodigestor para produção de energia elétrica - estudo de caso em confinador suíno. 2014. 34 f. Trabalho de Conclusão de Curso (Graduação em Engenharia Química) - Universidade Federal de Alfenas, Poços de Caldas, 2014.

FUNDAÇÃO APERAM ACESITA. Tecnologias alternativas: tipos de materiais para abastecimento. Cartilha. 2011.

IBAMA. Lei n 9.605, de 12 de fevereiro de 1998. Dispõe sobre Crimes Ambientais.

SCAPINELLO, J.; MUNARINI, A. C.; FRANCO, G. M. de S.; MAGRO, J. D. Avaliação de um sistema de tratamento anaeróbio de dejetos suínos. 2011. 13 f. Dissertação (Mestrado em Ciências Ambientais) - Universidade Comunitária da Região de Chapecó, Santa Catarina, 2011.

VIVAN, M.; KUNZ, A.; STOLBERG, J.; PERDOMO, C.; TECHIO, V. H. Eficiência da interação biodigestor e lagoas de estabilização na remoção de poluentes em dejetos de suínos. Revista Brasileira de Engenharia Agrícola e Ambiental, v. 14, n. 3, p. 320-325, 2010. 